\title{
Policy Implications for Global Pervasive Nanotechnology Innovation
}

\section{Farid Menaa*}

Department of Pharmaceutical Sciences and Nano-Medicine Fluorotronics, Inc. San Diego, California, USA

Nanotechnology is a fast growing branch of engineering that usually deals with dimensions and tolerances of less than 100 nanometers. Nanotechnology is an emerging and disruptive technology at the crossroads of several scientific fields, ranging from medicine (e.g. cancer nanotheranostics) to electronics (e.g. biosensors) [1-3]. Due to its potential in fast innovation and its socio-politico-economic impacts worldwide, it creates new opportunities and challenges that address global issues. Nanotechnology is promising "more for less" to several long-standing environmental and human concerns. Nevertheless, in some segments (e.g. medicine, food and cosmetics), nanosafety and "nano-ethical" concerns still require to be better addressed [4]. Indeed, according to one of my preliminary randomized surveys involving worldwide participants $(n=100)$ aged from 15 to 80 years, $45 \%$ felt skeptical about nanotechnology, 35\% felt good/enthusiastic and $20 \%$ did not know it, although the reality is that we use nanotechnologies in our everyday life (Figure 1).

Many countries have developed nanotechnology programs since the US National Nanotechnology Initiative was announced in 2000 [5-8]. According to the World Economic Forum's Annual Global Competitiveness Report 2011 [9], nanotechnology is attracting more public and private fundings than any other area of technology worldwide, estimated in US \$ multi-billion. Regulation of nanotechnology by the establishment of internationally-agreed policies is a must to objectively deal with several topics of increasing governmental interest such as international trade of nanoproducts, intellectual property, and nanotechnological transfers. The issue of nanotechnology global governance (i.e. conciliation of diverging interests aka "coherent standardization agreement") and its overall impacts (including risks) are at the crossroads [10]. Therefore, the intervention of the worldwide societies (i.e. developed and developing countries), worldwide policymakers (e.g. OECD, UNESCO, ISO, IBSA, WPMN, WPN, FDA), stakeholders (e.g. private initiatives such as ICON, IRGC, public funding institutions such as WHO and UNEP) and the financial and insurance sectors, is required to undertake fairest decisions and define an appropriate model for nanotechnology regulation, considering the model of "responsible/pervasive innovation" [10]. Further, a framework for global legal authority and transjudicial cooperation is needed [11]. Besides, nanoscience and nanotechnology indicators shall give insights [12]. For instance, indicated stage of maturity of a given

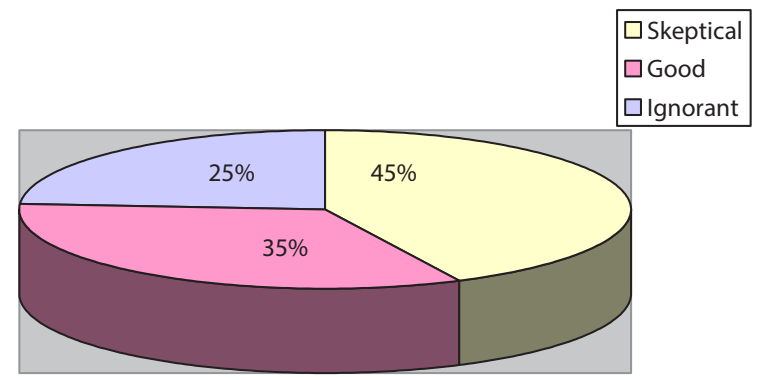

Figure 1: Data from preliminary international survey about the perception of nanotechnology. The randomized study, realized from January to December 2013 , involved worldwide participants $(n=100)$ aged from 15 to 80 years. nanotechnology can be used to depict scenarios for future evolution and for decision makers to design an appropriate strategy [12]. Also, key issues to reach a more objective dialogue include potential or confirmed risks, data transparency and accessibility (e.g. via openaccess online publications), society's opinion. Eventually, a balanced approach of risks and benefits of research and development (R\&D), commercialization and trade of nanoproducts, arising among public and private decision-makers, is important in an economy perspective.

Up-to-date, several countries including the BRICS (Brazil, Russia, India, China, South Africa), all the European Union Member States, most of the OECD (e.g. Japan, Taiwan, Israel), and also Korea, Argentina, Malaysia, Turkey, Morocco, Saudi Arabia, have adopted public policies supportive of research and innovation in the field of nanoscience and nanotechnology (i.e. precautionary approach with regards to health, environment, legal and ethical issues) [10].

Nanotechnology and below scales technologies (e.g. picotechnology) are quite promising for $\mathrm{R} \& \mathrm{D}$ applications worldwide, then impact our societies by bringing new solutions but shall be quite well regulated to avoid that these small worlds generate big issues.

\section{References}

1. Menaa B (2011) The Importance of Nanotechnology in Biomedical Sciences. J Biotechnol Biomaterial 1: 105e.

2. Menaa F, Menaa B (2012) Development of Mitotane Lipid Nanocarriers and Enantiomers: Two-in-One Solution to Efficiently Treat Adreno-Cortical Carcinoma. Curr Med Chem 19: 5854-5862.

3. Menaa F (2013) Functional Graphene-Based Nanobioimaging Platforms: New Powered Real-Time Interfaces. J Mol Imaging Dynam 2: e103.

4. Menaa F (2013) When Pharma Meets Nano or The Emerging Era of NanoPharmaceuticals. Pharmaceut Anal Acta 4:223.

5. National Nanotechnology Initiative (2000)

6. Roco MC (2007) National Nanotechnology Initiative - Past, Present, Future Handbook on Nanoscience, Engineering and Technology, (2nd edn), Taylor and Francis: 3.1-3.26.

7. Sargent Jr. JF (2013) The National Nanotechnology Initiative: Overview, Reauthorization, and Appropriations Issues. Congressional Research Service 1: 65.

8. Harper T (2011) Global Funding of Nanotechnologies \& Its Impact. Cientifica 1-8.

9. Schwab K (2010) The Global Competitiveness Report 2010-2011. World Economic Forum 1-516.

10. Roure FD (2008) Nanotechnology Global Governance at the Crossroads Center for Policy on Emerging Technologies (C-PET), Washington, D.C Transatlantic Dialogue on Emerging Technologies, London, UK.

*Corresponding author: Farid Menaa Director, Department of Pharmaceutical Sciences and Nano-Medicine Fluorotronics, Inc. San Diego, California, USA, Tel: (+1) 858-274-2728; E-mail: dr.fmenaa@gmail.com

Received December 26, 2013; Accepted December 28, 2013; Published December 31, 2013

Citation: Menaa F (2013) Policy Implications for Global Pervasive Nanotechnology Innovation. Pharm Anal Acta 5: e162. doi: 10.4172/2153-2435.1000e162

Copyright: (C) 2013 Menaa F. This is an open-access article distributed under the terms of the Creative Commons Attribution License, which permits unrestricted use, distribution, and reproduction in any medium, provided the original author and source are credited. 
Citation: Menaa F (2013) Policy Implications for Global Pervasive Nanotechnology Innovation. Pharm Anal Acta 5: e162. doi: 10.4172/21532435.1000e162

Page 2 of 2

11. Miller SE (2004) Confronting Tomorrow: U.S., E.U. Legal Frameworks IIIequipped for Technology's Future. New York Law Journal 232: 109.
12. Compano R, Hullmann A (2002) Forecasting the development of nanotechnology with the help of science and technology indicators. European Commission. IPO Publishing. 